\title{
Mycological Insights Into Wetland Fungal Communities: The Mycobiome of Camassia in the Pacific Northwest
}

\author{
Gretchen Freed, ${ }^{1}$ Daniel Schlatter, ${ }^{2}$ Timothy Paulitz, ${ }^{2, \dagger}$ and Frank Dugan ${ }^{3}$ \\ ${ }^{1}$ Washington State University, Department of Plant Pathology, Pullman, WA 99164 \\ ${ }^{2}$ U.S. Department of Agriculture-Agricultural Research Service, Wheat Health, Genetics and Quality Research Unit, Pullman, WA 99164 \\ ${ }^{3}$ U.S. Department of Agriculture-Agricultural Research Service, Western Regional Plant Introduction Station, Pullman, WA 99164
}

Accepted for publication 3 August 2019.

\section{ABSTRACT}

Fungal communities in ephemeral wetland habitats of the Pacific Northwest (PNW) are poorly understood. Because Camassia (camas) populations are a distinctive component of native plant communities in wetland areas of the PNW, camas plant tissue, seed, and associated soil samples were taken from populations growing in wetland habitats in Oregon, Idaho, and Washington. Enumeration of fungal taxa from aboveand below-ground camas tissues was accomplished using highthroughput sequencing of fungal internal transcribed spacer genes. Operational taxonomic units (OTUs) affiliated with at least 200 fungal families were found in root, tunic, leaf, rhizosphere, and proximal soil samples ( $n=2,984$ OTUs). Significant variation in fungal community composition was explained by sample type, habitat of origin, and their interaction. Taxa related to Cladophialophora, Cadophora, and Exophiala, believed to be dark septate endophytes together with Penicillium, Ceratobasidium, and Ilyonectria were differentially abundant in roots compared with the rhizospheres. Seed-associated communities comprised just 127 OTUs but were highly diverse with at least 50 families detected. Comparison of communities from camas seeds, leaves, roots, and rhizospheres revealed 68 fungal taxa in common, including Alternaria, Fusarium, Selenophoma, Cladosporium, Cryptococcus, and Sporobolomyces. This study provides a baseline understanding into the composition and diversity of fungal communities associated with camas growing in wetland habitats in the PNW.

Keywords: ecosystems, endophytes, microbiome, mycology, natural habitats, rhizosphere and phyllosphere
Camas (Camassia) bulbs retain profound cultural value as an important food resource and article of commerce that were utilized for millennia by over 60 indigenous groups across western North America (Beckwith 2004; Thoms 1989; Turner and Turner 2008; Weddell 2002). The intensification in the management of camas bulbs and their further processing for winter storage is thought to have occurred for 5,000 years or more (Lyons and Ritchie 2017; Thoms 1989; Turner and Turner 2008). Meriwether Lewis mistook

\section{Corresponding author: T. Paulitz; timothy.paulitz@ars.usda.gov}

Funding: This research was supported by the U.S. Department of AgricultureAgriculture Research Service (USDA-ARS base funds) Plant Germplasm Introduction and Testing Unit and the Wheat Health, Genetics and Quality Research Unit, Pullman, WA.

*The $e$-Xtra logo stands for "electronic extra" and indicates that three supplementary figures and 10 supplementary tables are published online.

The author(s) declare no conflict of interest.

This article is in the public domain and not copyrightable. It may be freely reprinted with customary crediting of the source. The American Phytopathological Society, 2019 dense populations of the violet-blue camas flowers as sheets of water, "the quawmash is now in blume and from the color of its bloom at a short distance it resembles lakes of fine clear water" (https://lewisandclarkjournals.unl.edu/item/lc.jrn.1806-06-12). The decline of vast camas habitats in Oregon, Washington, and Idaho has occurred rapidly over the past 180 years as a direct result of sweeping changes in the regional landscape that has been altered irreversibly by the drainage of the majority of wetlands to advance agricultural production and land development (Beckwith 2004; Thoms 1989; Weddell 2002). The remaining camas populations are fragmented, widely scattered across the region and are found in habitats that experience soil saturation from late fall through early summer.

Camassia quamash (Pursh) Greene, common camas, is endemic to the Pacific Northwest (PNW) region of the United States and Canada. Although related to Hosta, Agave, and Yucca (Asparagaceae: Agavoideae) (Angiosperm Phylogeny Group 2009), camas populations grow in wetland areas of prairies, forest meadows, and open savannas (Beckwith 2004; Klinkenberg 2017; Turner and Peacock 2005). Camas is classified as a geophyte, a bulbous perennial that produces beautiful spring foliage annually for 20 years or more (Bell and Bryan 2008; Thoms 1989). Camas 
phenology coincides with the wetland soil moisture cycle (Hebda 1992); camas bulbs germinate in late fall when the rains start and the flowers bloom midspring (MacLay 1928; Stevens et al. 2001; Thoms 1989). Camas produces true seed ( $>70$ seeds/plant) that are dispersed in early summer after which the leaves and outer bulb layers (tunic) senesce. The bulb enters dormancy through the hot, dry summer and early fall months.

Fungal communities are hypothesized to benefit wetland plants via facilitation of nutrient cycling in the soil through the decomposition of plant litter (van der Valk 2012). The decomposition of plant litter in wetland ecosystems is often much slower than in terrestrial ecosystems as a result of reduced fungal activity when soil oxygen availability is low (White and Reddy 2009). Thus, wetland soils often accumulate more organic matter compared with terrestrial ecosystems (Bridgham and Lamberti 2009; Cherry 2011; van der Valk 2012; White and Reddy 2009) that results in carbon sequestration in the plant litter, an attribute of wetland ecosystems (Cherry 2011; Dise 2009; van der Valk 2012; Verhoeven 2009). Furthermore, restoration of wetland areas is important for the preservation of the biodiversity of native plant species and the wildlife dependent on this habitat (Krueger et al. 2014).

Wetland restorationists in the Willamette Valley, OR consider camas a keystone perennial in native plant communities (Krueger et al. 2014; Steeck 2014). The establishment of camas populations in restoration sites has proven to be a challenge, although seed increase plots in native plant nurseries have successfully produced camas in monoculture (Boyer 2008). Camas seeds, procured from nursery seed increase plots, are sown into wetland prairie sites in efforts to reestablish camas populations (Krueger et al. 2014; Steeck 2014). Camas plant establishment can be difficult due to seedling mortality and/or competition in mixed plant communities as camas takes 3 to 4 years to produce its true seed (Thoms 1989). Some seed-associated fungi may influence the survival of seedlings, facilitate the persistence of a plant in natural or restored plant communities (Klaedtke et al. 2016), and colonize other plant tissues or plant-associated soils such as the rhizosphere (Barret et al. 2015; Klaedtke et al. 2016; Nelson et al. 2018). Fungal communities associated with seeds are thought to provide inoculum for colonization of seedling tissues (Barret et al. 2015; Nelson 2018). Seedling establishment is critical to restoration efforts and plant distribution in wetland ecosystems (Crocker et al. 2016; Nelson 2018).

Investigations of fungal communities associated with camas plant tissues, seeds, and associated soils will enhance our understanding of wetland ecology. In this study, we assess both below- and aboveground fungal communities associated with camas growing in biogeographically distinct wetland habitats. Little is known of the composition and diversity of the fungal taxa associated with camas populations growing in ephemeral soil moisture conditions. Our primary objectives were to (i) explore the composition of camas fungal communities in the six camas sample types taken from six habitats; (ii) evaluate the association of camas sample type and habitat with fungal community diversity; and (iii) compare camas seed-associated fungal communities to the taxa detected in the root, leaf, and rhizosphere.

\section{MATERIALS AND METHODS}

Overview. Camas plants and associated soils were sampled from six biogeographically distinct wetland habitats in Washington, Idaho, and Oregon (Fig. 1A and B). The composition and diversity of fungal communities associated with camas plant tissues and associated soils were explored using culture-independent highthroughput DNA sequencing (Illumina MiSeq). Soil edaphic characteristics of the habitats were also evaluated to assess associations with fungal communities. Camas habitats chosen for this study were favorable for camas populations and comprised herbaceous vegetation, soil conditions that experienced seasonal saturation and full exposure to the sun. In 2016, we sampled garden and meadow habitats within 30 miles of Pullman, WA. We also sampled savanna, serpentine, swale and mitigation habitats in western Oregon. We used high-throughput sequencing of fungal internal transcribed spacer (ITS) genes associated with camas plant tissue and soil samples to characterize fungal communities within and among habitats and sample types (plant part). In 2017, camasassociated soil samples were collected from each of the six habitats to evaluate the relationship between soil edaphic characteristics and camas-associated fungal communities.

Camas habitats. The selected habitats were comprised of a garden habitat in Whitman County, WA; a meadow wetland habitat in Latah County, ID; a savanna wetland habitat in Curry County, OR; a serpentine wetland habitat in Josephine County, OR; a swale wetland habitat in Lane County, OR; and a mitigation wetland habitat in Lane County, OR. Detailed information about sites is given in Supplementary Table S1.

Plant and soil sampling. In 2016, we sampled six camas habitats (garden, meadow, savanna, serpentine, swale, and mitigation) for

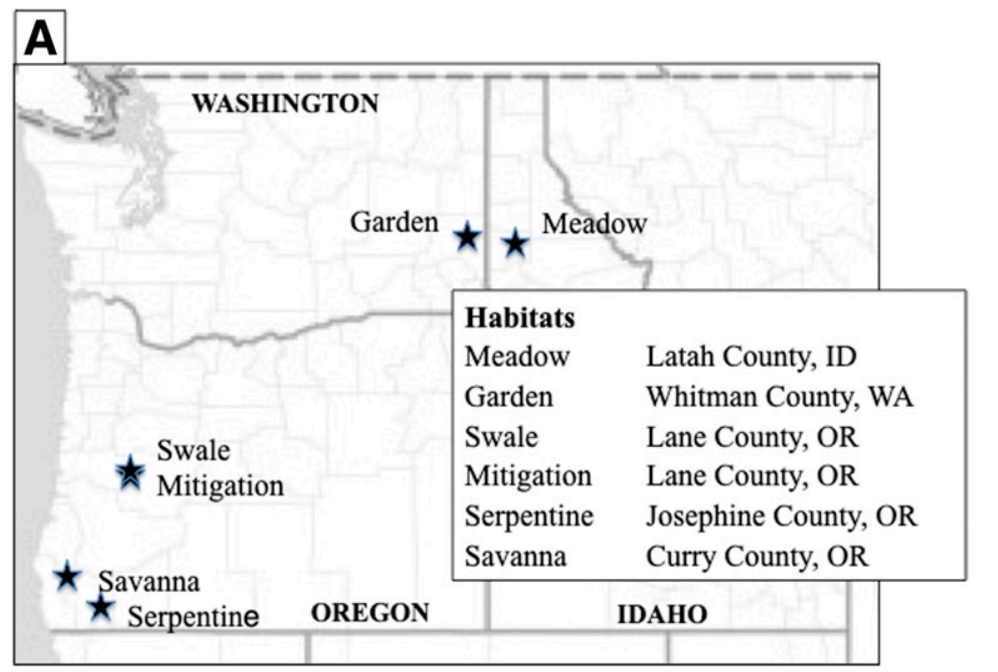

\begin{tabular}{|l|}
\hline B \\
\hline Sample Types \\
Tunic \\
Root \\
Leaf \\
Seed \\
Rhizosphere \\
Proximal Soil \\
\hline
\end{tabular}
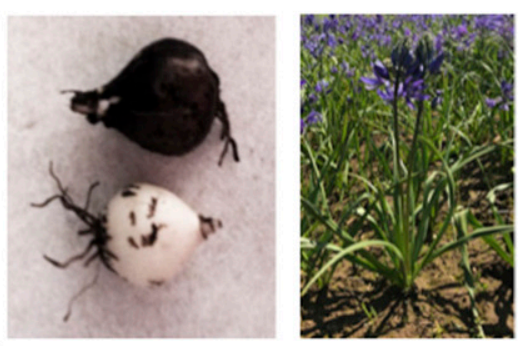

Fig. 1. A, Camas habitats sampled across the Pacific Northwest U.S.A. B, Camas bulbs with and without a tunic (left) and flowering camas (right). 
culture-independent methods to explore fungal community composition and diversity associated with camas plant tissues (root, tunic, and leaf) and associated soils (rhizosphere and proximal soil). In May, 10 camas plants were sampled from the each of the six habitats and six plant and soil samples per habitat were used to identify and enumerate fungi in camas root, tunic and leaf tissues and rhizosphere and proximal soils. Samples were located $>0.3 \mathrm{~m}$ apart in the garden habitat and $>5.0 \mathrm{~m}$ apart in the remaining habitats. Each bulb, including tunic, root and attached soils was placed in a labeled paper bag. Two leaf samples from each specimen were placed in a labeled envelope. Proximal soil (approximately $15 \mathrm{~g}$ ) for each sample was collected into a conical tube (Corning, Inc., Corning, NY) from the depth of the harvested camas bulb and 8 to $10 \mathrm{~cm}$ from the plant. All samples were transported on ice to the lab. Six camas plants were collected from the savanna and serpentine habitats by two Siskiyou-Rogue River National Forest botanists. The botanists used the sample collection protocol described above.
The samples were held on ice and shipped overnight to Pullman, WA. The six samples were each placed in a plastic box with holes and a lid and stored at $-20^{\circ} \mathrm{C}$ for the culture-independent study.

Seed sampling. Camas seeds were sampled from the garden, meadow, swale and mitigation habitats. Mature seeds were collected in early July from the garden and meadow habitats. Seeds were collected from camas plants that had ripe, open seed capsules. Sampled plants were located at least $0.3 \mathrm{~m}$ apart in the garden habitat and at least $5 \mathrm{~m}$ apart in the meadow habitat. Seeds of each plant were collected in individually labeled coin envelopes, returned to the lab and stored at $4^{\circ} \mathrm{C}$ in a closed container with a desiccant. Seed was not collected at the savanna and serpentine site, because plants were in flower at the time of sampling.

High-throughput sequencing of fungal ITS genes. DNA sequencing method. Genomic DNA was extracted from camas tunic, root and leaf tissues, seed, rhizosphere, and proximal soil samples and stored at $-20^{\circ} \mathrm{C}$. Preparation of the rhizosphere samples

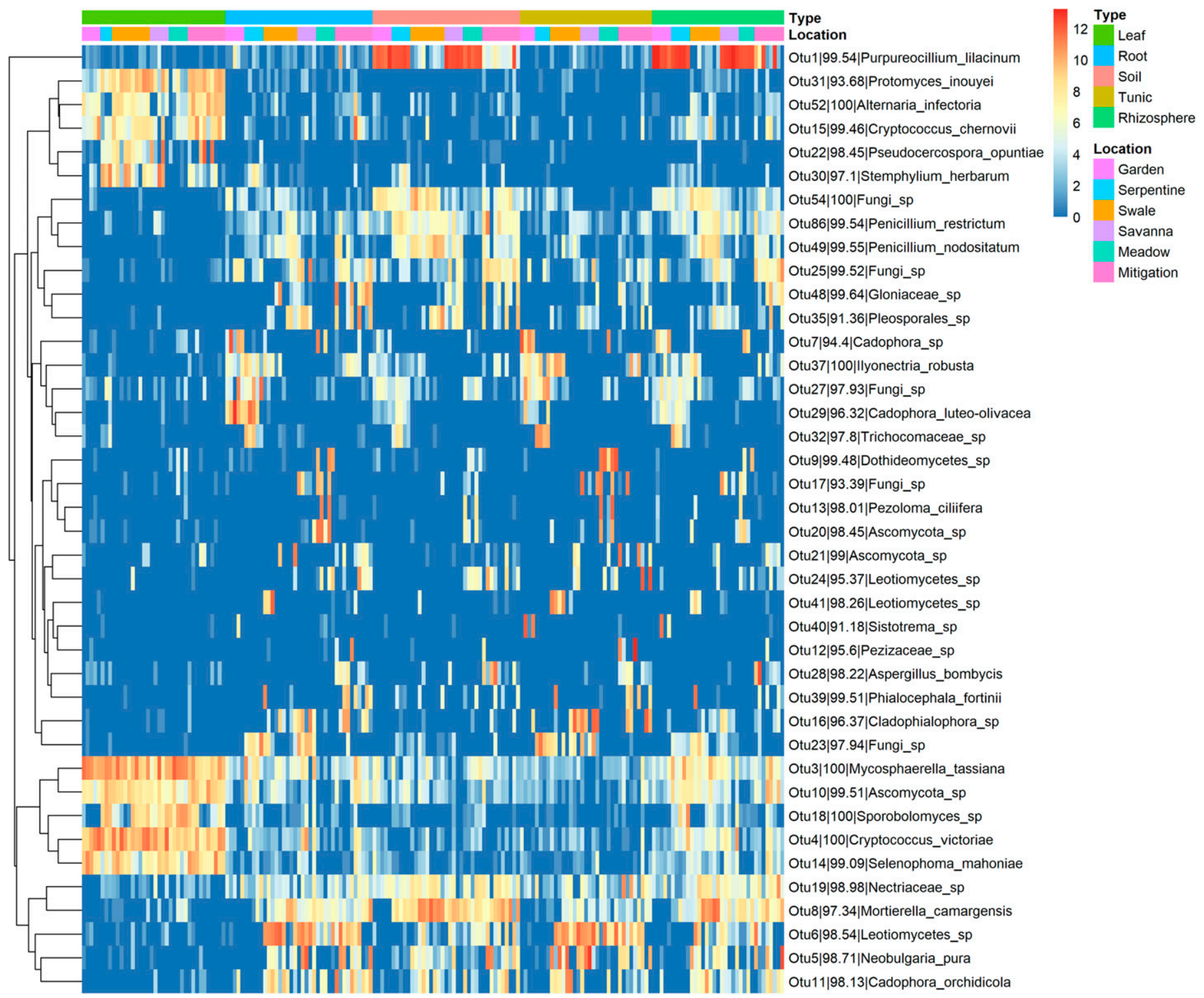

Fig. 2. Heatmap of fungal operational taxonomic unit (OTU) abundances from five plant tissue types or associated soils from sampled camas plants. Plants were sampled from six habitats across the Pacific Northwest U.S.A. based on high-throughput DNA sequencing. The list of fungal taxa comprised $>0.005 \%$ of the total OTUs detected in each sample type and habitat. Heatmap color legends show the sample types, habitats, and log ${ }_{2}^{-}$ transformed OTU abundance of the fungal taxa represented. Heatmap color legend shows the $\log _{2}$-transformed OTU abundances of taxa for each fungal family and order represented. 
consisted of sonication of the unwashed roots in $1 \mathrm{ml}$ of sterile distilled water for $10 \mathrm{~min}$. The roots were transferred aseptically to extraction tubes. The sonicate suspension was centrifuged $(10,000 \mathrm{rpm})$ for $4 \mathrm{~min}$ and the supernatant discarded. The tunic tissues were sonicated in the same manner as the roots. The seed was not surface-disinfested to facilitate the detection of fungal taxa on and in the seed. Ten seeds/sample were removed from the closed seed capsules of each camas plant, placed in individual sample Eppendorf tubes and stored at $-20^{\circ} \mathrm{C}$. The garden and meadow seed samples $(10$ seeds/sample) were each placed in a surface-disinfested mortar and the seed coats cracked using the surface-disinfested pestle and then placed in individual sample Eppendorf tubes. DNA was extracted from the tunic, root, leaf tissues, and seed using the Power Plant Pro DNA Isolation Kit and from the rhizosphere and proximal soils using the Power Soil DNA Isolation Kit (Mo-Bio Laboratories, Inc., Carlsbad, CA). Negative control samples were produced using sterile distilled water for both the Power Plant Pro DNA and the Power Soil DNA Isolation Kits. The prepared DNA was stored at $-20^{\circ} \mathrm{C}$.

Illumina MiSeq sequencing and bioinformatics. The extracted genomic DNA of each of the samples (fungal communities) was sent to the University of Minnesota Genomic Center (UMGC) for PCR amplification of the ITS1 region using the ITS1-F (5'CTTGGTCATTTAGAGGAAGTAA- $3^{\prime}$ ) and ITS2 (5'-GCTGC GTTCTTCATCGATGC-3') primer pair (Gardes and Bruns 1993). The amplicons were pooled and sequenced using the MiSeq 600 cycle V3 kit. Forward and reverse sequence reads were paired with PEAR v0.9.6 (Zhang et al. 2014). Forward and reverse primers were trimmed and sequences with less than $150 \mathrm{bp}$ and any $\mathrm{N}$ bases were discarded with cutadapt (Martin 2011). Operational taxonomic units (OTUs) were clustered according to the UPARSE pipeline (Edgar 2013). Briefly, high-quality sequences were used for OTU clustering after filtering the sequences to produce a maximum expected error of $<1$. Dereplication and removal of singletons was accomplished using VSEARCH (Rognes et al. 2016). OTUs were clustered at $97 \%$ similarity with USEARCH v8.1 (Edgar 2010) and raw reads were mapped to OTU representative sequences to generate an OTU table. Taxonomy was assigned to OTUs using BLAST+ (Altschul et al. 1990) and the UNITE ITS reference database (Abarenkov et al. 2010). OTUs with an e-value $<10^{-40}$, a match length $<75 \%$ or a total sequence count $<5$ were discarded. The OTU table was rarefied to 10,000 sequences/sample for the root, tunic, leaf, rhizosphere, and proximal soil samples, with five biological replications for statistical analyses. Fungal communities from camas seeds were dominated by plant-derived sequences, perhaps due to coamplification of plant DNA and/or low biomass of fungi associated with camas seeds. As a result of few fungal sequences detected in seeds, these samples were rarefied to a much lower sequence depth $(n=200$ sequences/ sample) prior to statistical analyses.

2017 soil analyses. Soil sampling and analysis. Five soil samples (approximately $100 \mathrm{~g}$ each) were collected from each of the garden, meadow, serpentine, savanna, swale, and mitigation habitats for analyses of edaphic characteristics. Soil was sampled 8 to $10 \mathrm{~cm}$ from growing camas bulbs and each was placed in a labeled conical tube. Soil samples were transported on ice and held at $4^{\circ} \mathrm{C}$ until delivery to the Oregon State University (OSU) Central Analytical Lab, Corvallis, OR, and dried within $24 \mathrm{~h}$ of reaching that lab. Soil $\mathrm{pH}$ was measured using a 1:2 soil/water suspension with a benchtop pH meter (Hanna Instruments, Limena, Italy). Total carbon and nitrogen concentrations were quantified using the vario MACRO Cube (Elementar, Langenselbold, Germany). Organic matter was reported as twice the carbon concentration (Pribyl 2010). Particle size distribution analysis was used to assess soil texture in terms of the percentage clay, silt, and sand components.
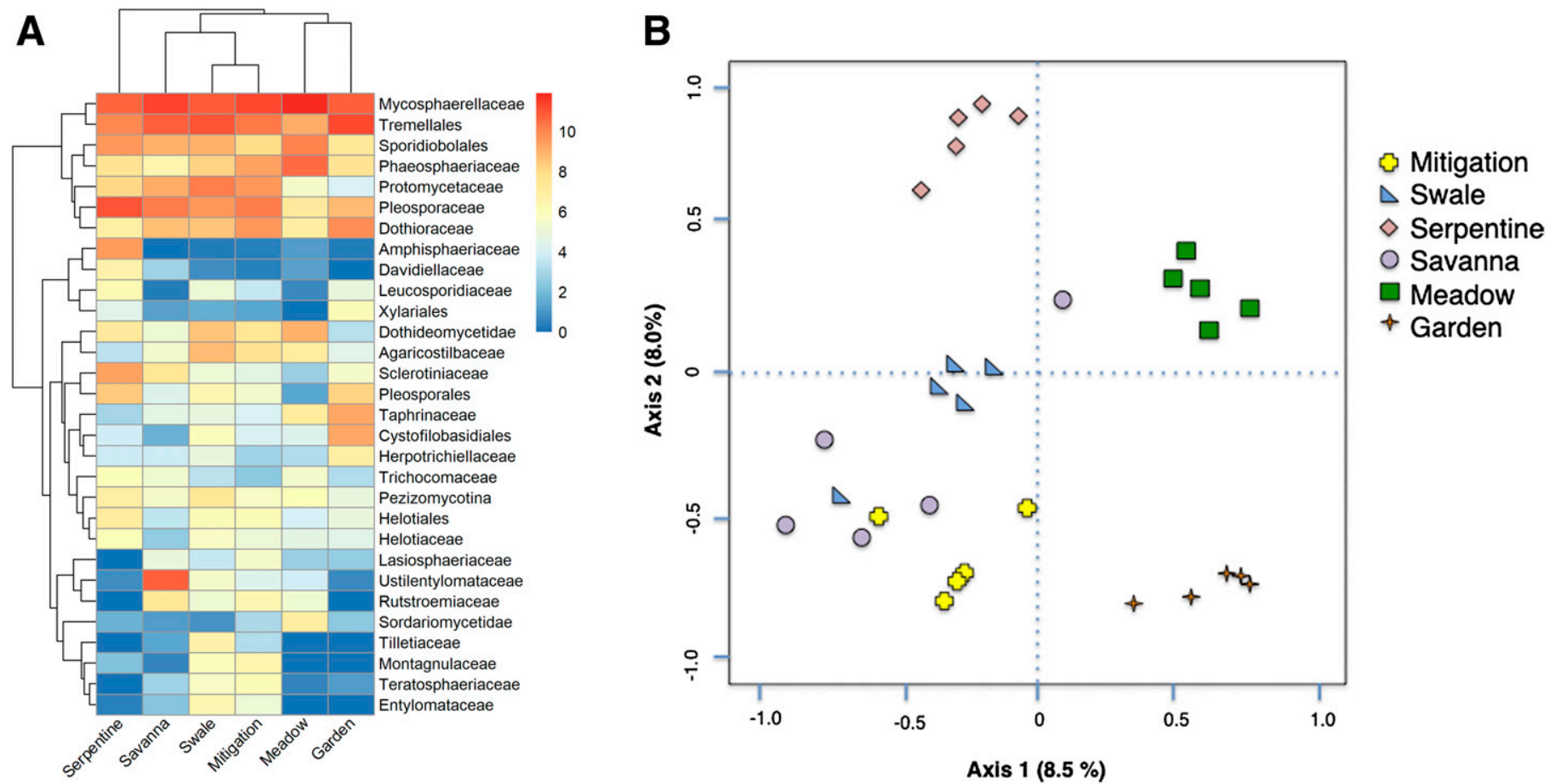

Fig. 3. A, Heatmap of fungal operational taxonomic unit (OTU) abundances and B, principal components analysis (PCA) of fungal communities detected in camas leaves of sampled plants. Plants were sampled from six habitats across the Pacific Northwest U.S.A. Heatmap color legend shows the log $2^{-}$ transformed OTU abundances of taxa for each fungal family and order represented. Fungal taxa listed comprised $>0.001 \%$ of the fungal community detected in each habitat. B, PCA ordination of the plotted fungal communities was based on Hellinger-distance similarity (Borcard et al. 2011). PCA axes 1 and 2 explained $16.5 \%$ of the total variance in fungal communities. 
Data analyses. The fungal OTU table was analyzed using $\mathrm{R}$ Version 3.4.0 and the vegan, gclus, and pheatmap packages (Hurley 2012; Kolde 2011; Oksanen 2011). Two-way permutational multivariate analysis of variance (PERMANOVA) with Bray-Curtis dissimilarity, was used to test the significance of the main effects of tissue and habitat, and their interaction on fungal community composition. One-way PERMANOVA was also used to test the effect of habitat with each of the sample types. The PERMANOVAs were calculated (nperm $=999$ ) using vegan. Venn diagrams of shared and unique fungal taxa among the sample types and were developed manually. Heatmaps, using $\log _{2}$-transformed sequence counts for each sample type were used to examine the abundances of the prominent fungal families and orders in each habitat and were produced using gclus and pheatmap. Principal components analyses (PCA) of each sample type were performed using OTU tables transformed into Hellinger distances using vegan (Borcard et al. 2011). DESeq2 was used to identify differentially abundant OTUs among sample types using the following model: $\sim$ habitat + sample type. Briefly, differential abundant OTUs contrasting the rhizosphere/root, root/seed, rhizosphere/seed, and leaf/seed fungal communities were considered to be those with base means $>30$ and an adjusted $P<0.1$, which controlled the false discovery rate for. The edaphic data $(\mathrm{C}: \mathrm{N}$ ratio, $\mathrm{pH}$, organic matter, and percent clay, silt, and sand) were standardized to a zero mean and unit variance to scale the values for statistical comparison. Kendall tau rank correlation of the standardized edaphic variables was calculated to test the significance of bivariate covariance of each set of edaphic variable pairwise comparisons (Borcard et al. 2011). Fungal richness and diversity (Shannon's H' and Simpson's 1/D) were calculated and compared among groups with ANOVA using Tukey's honest significant difference tests for posthoc comparisons.

\section{RESULTS}

Fungal diversity in leaf, tunic, root, rhizosphere, and soil communities. The two-way PERMANOVA fungal community similarity showed that fungal communities differed significantly among the five sample types and the six habitats $\left(R^{2}=0.12\right.$ and 0.20 , respectively, $P<0.001$ ) (Supplementary Table S2). Further, there was a significant interaction between sample type and habitat $\left(R^{2}=0.17, P<0.001\right)$. Considering each sample type, one-way PERMANOVA revealed significant differences in fungal consortia among habitats for communities associated with leaves $\left(R^{2}=0.40\right.$, $P<0.001)$, tunics $\left(R^{2}=0.35, P<0.001\right)$, roots $\left(R^{2}=0.30, P<\right.$ $0.001)$, and rhizospheres $\left(R^{2}=0.44, P<0.001\right)$ (Supplementary Table S3).

Significant variation in the leaf-associated communities was associated with differences in Protomyces, Alternaria, and Pseudocercospora, which tended to be more sparse in the below-ground fungal communities (Fig. 2). Alternately, Mortierella, Neobulgaria, and Cadophora were frequently found in below-ground communities but were rare in the leaf communities. Leaf communities were dominated by taxa affiliated with the Dothideomycetes, Sordariomycetes, and basidiomycetous yeasts. Leaf taxa within the Dothideomycetes included OTUs related to Mycosphaerellaceae (Cladosporium, Dissoconium, and Septoria), Pleosporaceae (Stemphylium, Alternaria, and Epicoccum), Phaeosphaeriaceae (Phaeosphaeria), Dioriaceae (Selenophoma), Montagnulaceae, and Teratosphaeriaceae (Fig. 3A; Supplementary Table S4). The Sordariomycetes OTUs were related to Amphisphaeriaceae (Truncatella), Sordariomycetidae, Lasiosphaeriaceae (Podospora), and Xylariaceae. The basidiomycetous yeast and yeast-like (hyphomycetes often with yeastlike states) taxa present were affiliated with
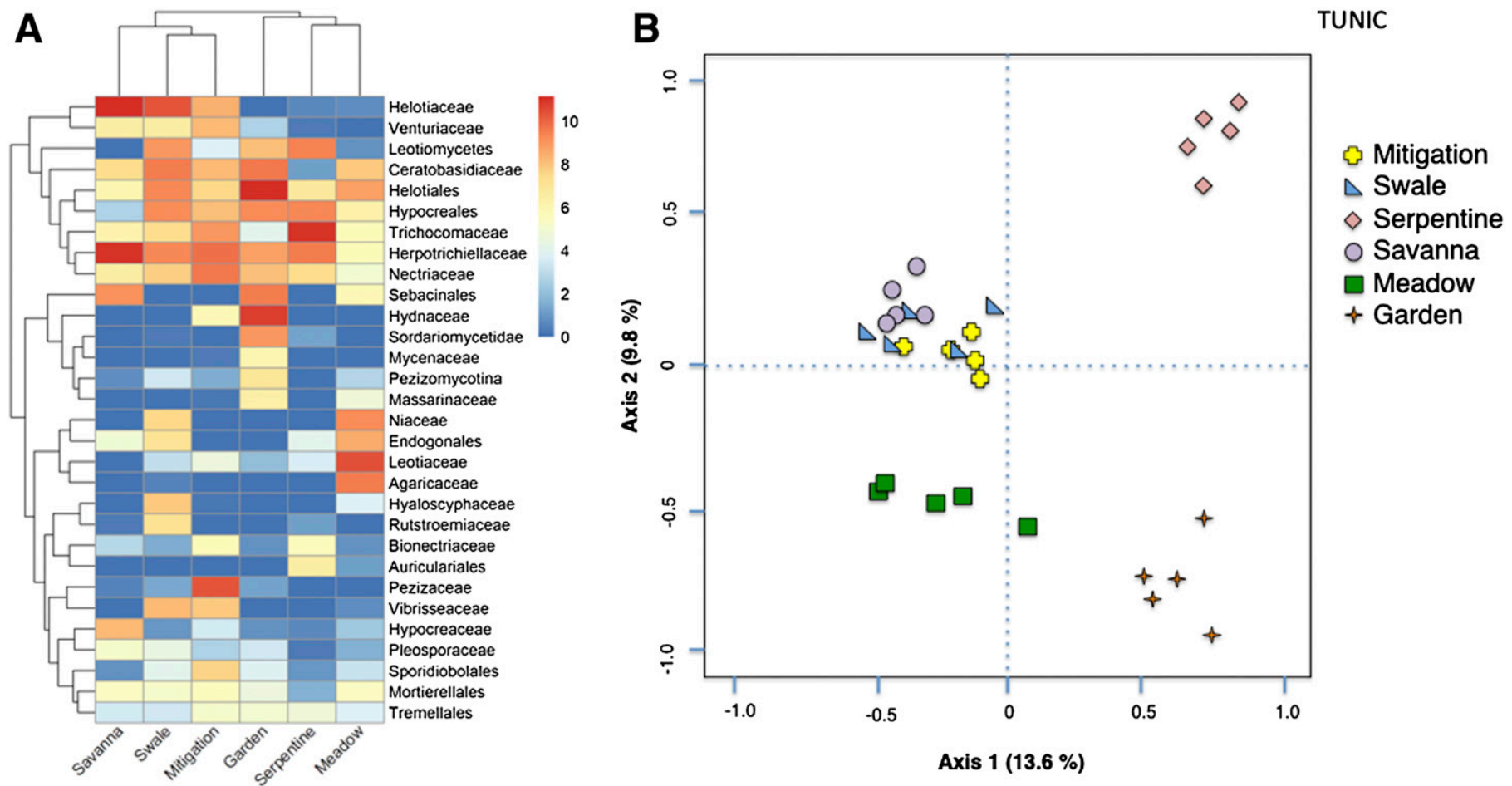

Fig. 4. A, Heatmap of fungal operational taxonomic unit (OTU) abundances and B, principal components analysis (PCA) of fungal communities detected in camas tunics of sampled plants. Plants were sampled from six habitats across the Pacific Northwest U.S.A. Heatmap color legend shows the log $2^{-}$ transformed OTU abundances of taxa for each fungal family and order represented. Fungal taxa listed comprised $>0.001 \%$ of the fungal community detected in each habitat. B, PCA ordination of the plotted fungal communities was based on Hellinger-distance similarity (Borcard et al. 2011). PCA axes 1 and 2 explained $23.4 \%$ of the total variance in fungal communities. 
Tremellales (Cryptococcus), Sporidiobolales (Sporobolomyces and Rhodoturula), and Ustilentylomataceae (Microbotryozyma).

Contrasting root, leaf, and proximal soil (Supplementary Fig. $\mathrm{S} 1$ ), the total number of taxa associated with the root samples was 1,314 OTUs, of which 185 OTUs were found only in the root samples including taxa of Sebacinales, Ceratobasidium (Agaricomycetes), Endogonales, and Chaetomiaceae (Sordariomycetes) (Supplementary Table S5). The total number of OTUs associated with the leaf samples was 1,264 and the 552 unique to the leaf samples were affiliated with Phaeosphaeria, Pseudocercospora, Septoria, Dissoconium, and Parastagonospora (Dothideomycetes), Protomyces and Taphrina (Taphrinomycetes), Bensingtonia
(Agaricostilbomycetes), and Microbotryozyma (Microbotryomycetes). The total number of taxa associated with the proximal soil samples comprised 1,924 OTUs, of which 725 OTUs in the proximal soil were not detected in the leaf or root tissues, including taxa affiliated with Purpureocillium and Chaetomium (Sordariomycetes) and Spizellomyces (Chytridiomycota) (Supplementary Table S6).

In the three-way comparison of the root, rhizosphere, and tunic (Supplementary Fig. S2), there were 898 OTUs associated with the tunic, 78 of which were unique including species of Serendipita (Agaricomycetes), Pyrenophora (Dothideomycetes), and Colletotrichum (Sordariomycetes) (Fig. 4A; Supplementary Table $\mathrm{S} 7$ ). The total number of taxa associated with the roots was 1,314
A

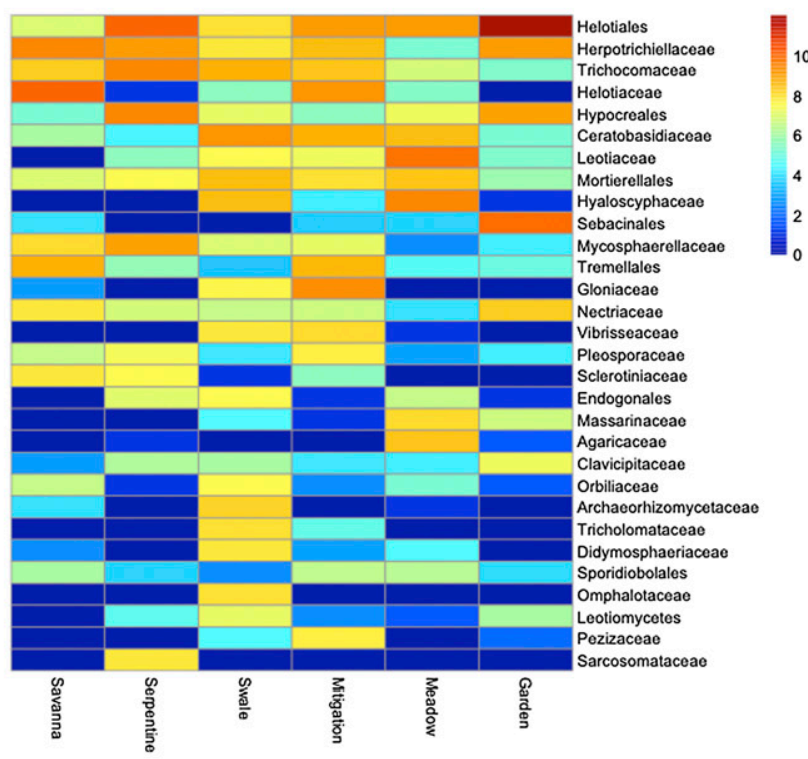

C

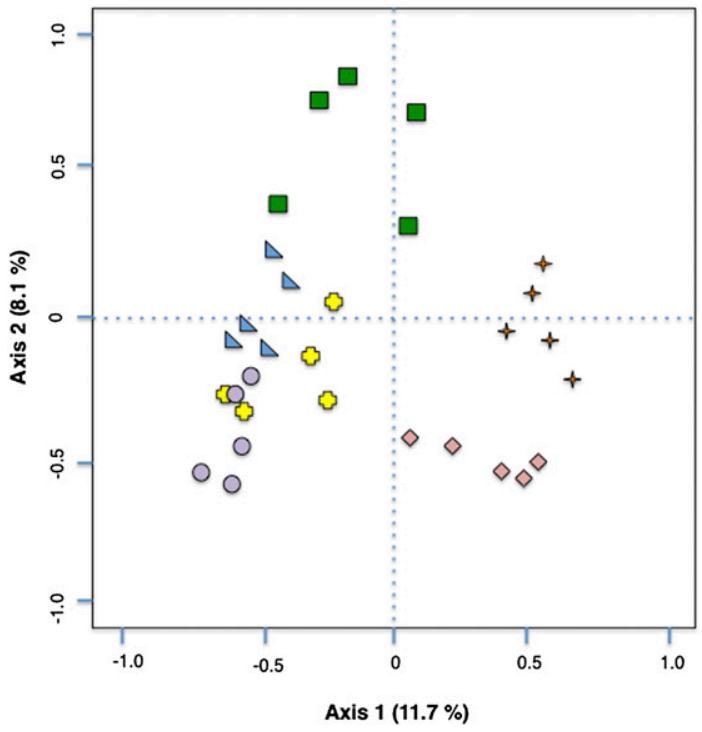

B

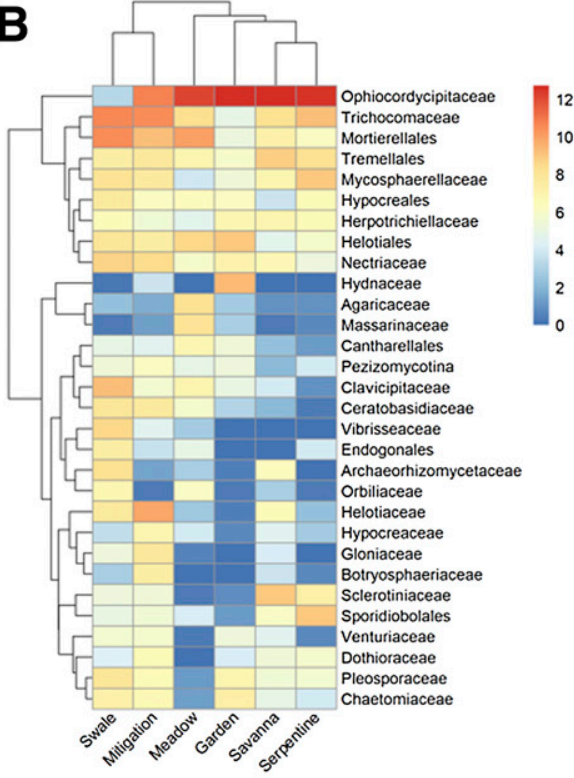

D

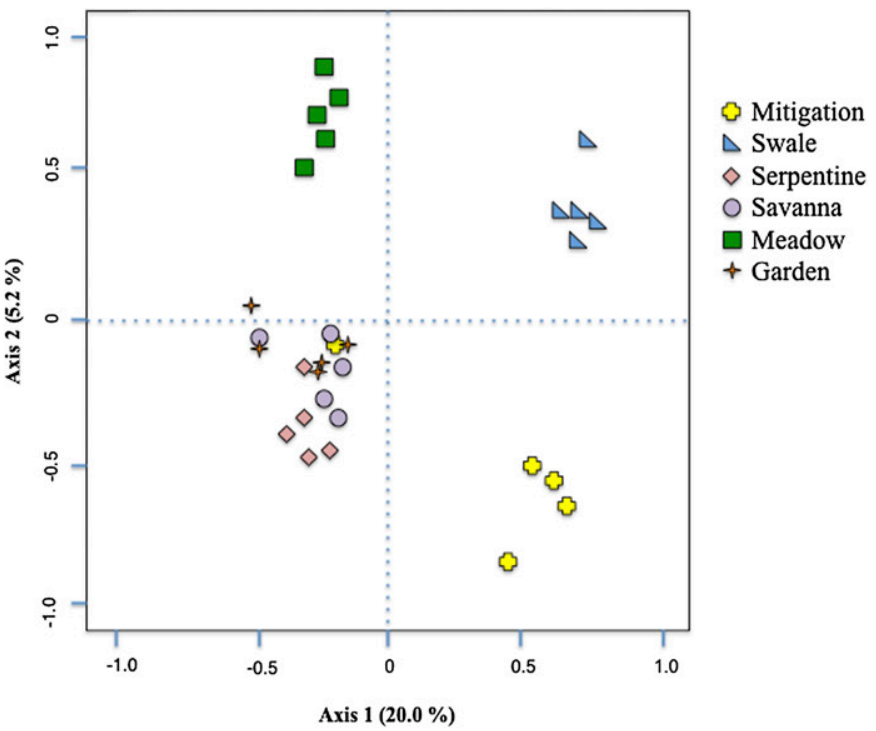

Fig. 5. A, Heatmaps of operational taxonomic unit (OTU) abundances for camas root fungal communities and B, the camas rhizosphere fungal communities from sampled camas plants. Plants were sampled from six habitats across the Pacific Northwest U.S.A. Heatmap color legend indicates the $\log _{2}$-transformed OTU abundances of taxa for each fungal family and order represented. The fungal taxa listed $>0.001 \%$ of the community abundance in each habitat. Heatmap color legend shows the $\log _{2}$-transformed OTU abundances of taxa for each fungal family and order represented. C, Principal components analysis (PCA) ordination of the plotted fungal communities for camas root fungal communities and $\mathbf{D}$, the camas rhizosphere fungal communities, based on Hellinger-distance similarity (Borcard et al. 2011). PCA axes 1 and 2 explained 19.8 and $25.2 \%$, respectively, of the total variance in fungal communities. 
OTUs, where 233 different OTUs were unique to the roots. Among these taxa affiliated with roots were Exophiala (Eurotiomycetes), Aspergillus (Trichocomaceae), and Endogonales (Zygomycetes). The total number of taxa associated with the rhizosphere was 1,591 OTUs, of which 481 OTUs were found only in the rhizosphere samples including Neobulgaria (Leotiomycetes), Rhodotorula (Microbotryomycetes), Diaporthe (Sordariomycetes), and Rhizopogon (Agaricomycetes) (Supplementary Table S8).
Root and rhizosphere communities displayed some interesting similarities and differences in community composition (Fig. 5A and B). The Helotiales (Cadophora), Leotiaceae (Neobulgaria), Trichocomaceae (Penicillium), Tremellales (Cryptococcus), Nectriaceae, Mycosphaerellaceae (Cladosporium), Ceratobasidiaceae (Ceratobasidium), Mortierellales (Mortierella), and Sebacinales (Serendipita) were detected in moderate to high abundances in both root and rhizosphere communities (Fig. 5A and B). The distinctive fungal taxa detected from the roots were OTUs in

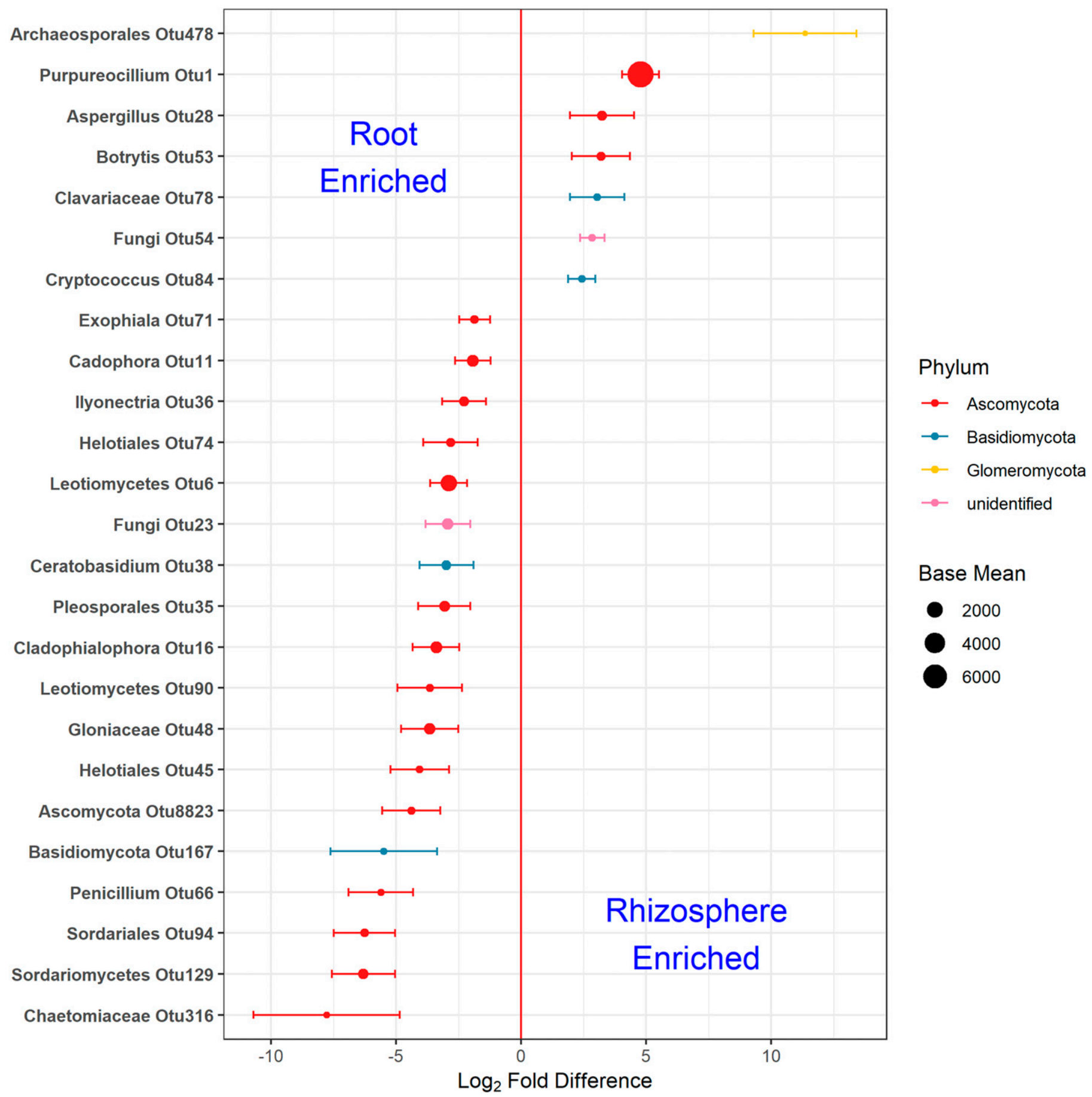

Fig. 6. Distribution of $\log _{2}$ fold changes indicate fungal operational taxonomic units (OTUs) differentially detected in camas rhizospheres compared with camas roots across six camas habitats across the Pacific Northwest U.S.A. Base means show the normalized sequence counts in each OTU. Only OTUs with base means $>30$ and Wald test adjusted $P<0.1$ are reported. Standard error bars display variance within each sample type with five replicate samples/habitat. 
Herpotrichiellaceae (Exophiala), Hypocreales (Ilyonectria), Leotiaceae (Alatospora), and Hyaloscyphaceae (Lachnum) (Fig. 5A). In contrast, the taxa exclusively associated with the rhizospheres included Ophiocordycipitaceae (Purpureocillium), Sclerotiniaceae (Botrytis), Sporidiobolales (Sporobolomyces), Pleosporaceae (Epicoccum), and Chaetomiaceae (Chaetomium) and were abundant (Fig. 5B). Taxa affiliated with Cladophialophora, Ceratobasidium, Cadophora, Ilyonectria, and Exophiala were significantly more abundant $(P<0.1)$ in root communities compared with those detected in the rhizospheres (Fig. 6).

Fungal diversity in camas seeds. Due to co-amplification of camas plant DNA, fewer fungal sequencing reads were obtained from seeds versus other sample types. For seed communities, 4,000 sequence reads clustered into 127 OTUs after filtering and rarefaction to 200 sequences per sample. Seed communities from different habitats, especially the swale, mitigation, meadow, and garden, differed significantly from each other $(P<0.001)\left(r^{2}=0.33\right)$. Three fungal phyla were detected in the seed-associated fungal communities, namely Ascomycota (70\%), Basidiomycota (29\%), and Zygomycota (1\%), which comprised at least 50 fungal families. The seed taxa primarily represented Dothideomycetes, Leotiomycetes, and Sordariomycetes $(50 \%)$ with the remainder of the moderately abundant taxa affiliated with Eurotiomycetes (13\%), Tremellomycetes (11\%), Agaricomycetes (10\%), Microbotryomycetes (6\%), and Ustilaginomycetes (5\%). Taxa assigned to Mortierellomycetes, Pezizomycotina, and Saccharomycetes each comprised $<1 \%$ of camas seed fungal taxa detected. There were three abundant genera present in all the habitats, namely Cladosporium, Selenophoma, and Cryptococcus (Fig. 7).

Seed communities harbored significantly greater abundances of some fungal taxa when contrasted to the root, rhizosphere, and leaves. For example, Fusarium (Figs. 8, 9, and 10) was more abundant in camas seeds versus roots, rhizospheres, and leaves. Alternaria, Selenophoma, Cladosporium, and Cryptococcus taxa were more abundant in the seed communities when contrasted to those of the roots and rhizospheres (Figs. 8 and 9). Common taxa among the seed, root, rhizosphere, and leaf communities included Sporobolomyces, Cladophialophora, Botrytis, Cadophora, Metacordyceps, Pseudocercospora, Penicillium, Neobulgaria, Sistrotrema, and Ilyonectria (Supplementary Table S9).

Alpha-diversity among locations and sample types. The richness and diversity of fungal communities varied significantly with habitat and sample type (ANOVA F $=6.53, P<0.001$ and $\mathrm{F}=47.13, P<0.001$, respectively). Interestingly, although the richness of fungal communities from soil and above-ground plant tissues varied significantly among habitats, the richness of communities from the rhizosphere and internal plant tissues did not differ significantly among habitats (Table 1). Similarly, Shannon diversity did not vary significantly among habitats for internal plant tissues, despite significant differences among habitats for proximal soils, rhizosphere, leaf, and seed communities (Table 2). Moreover, the richness of fungal communities tended to decrease successively from soil to rhizosphere,

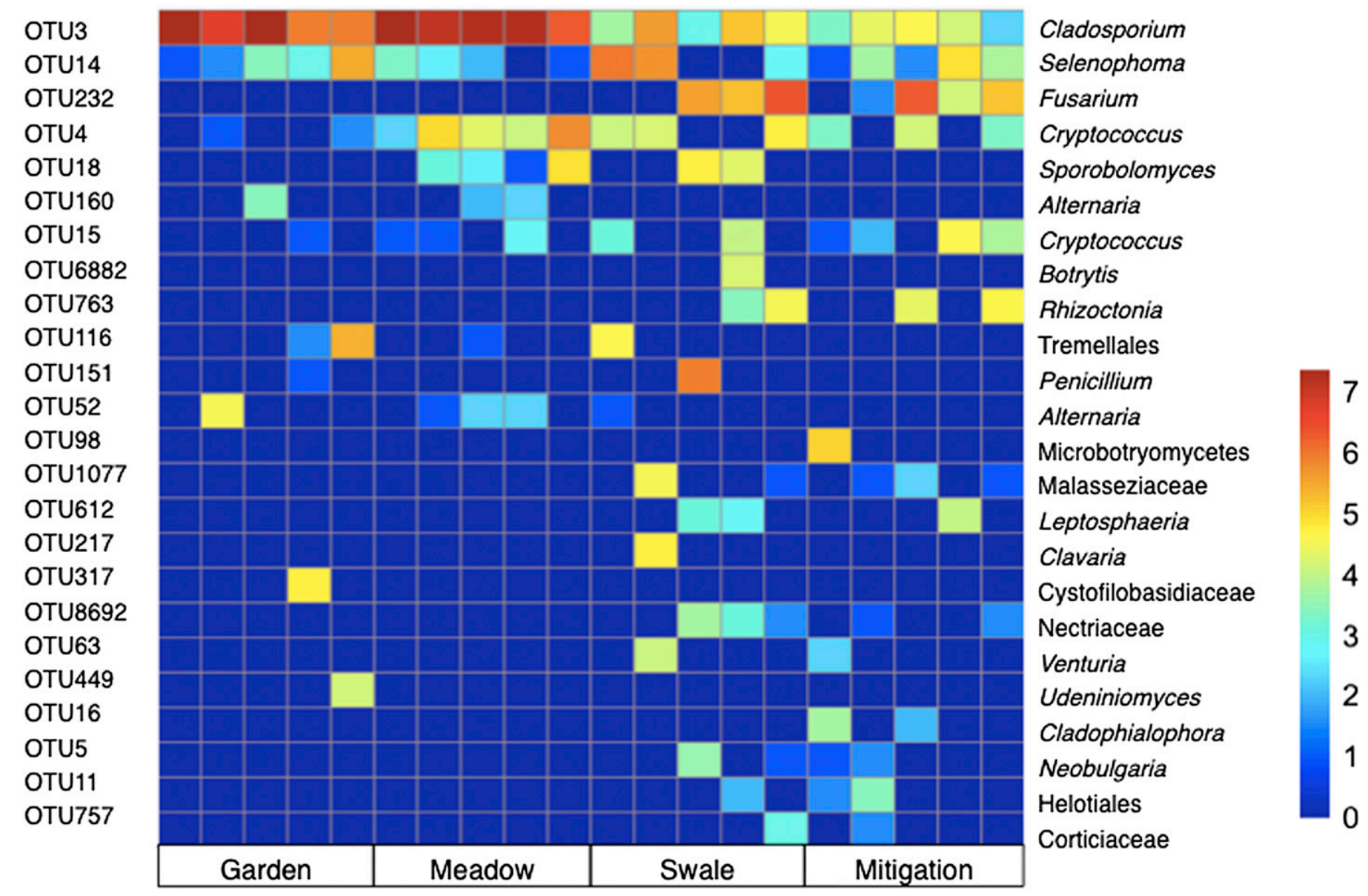

Fig. 7. Heatmap of operational taxonomic unit (OTU) abundances fungal taxa that were detected in camas seed. Camas seeds were sampled from four habitats across the Pacific Northwest U.S.A. Heatmap color legend shows the $\log _{2}$-transformed OTU abundance of each fungal taxon represented. Fungal taxa listed have abundances $>0.001 \%$ out of the total fungal community detected in each habitat. 
rhizosphere to roots, and roots to tunics, suggesting that plants limit the complexity of fungal communities in below-ground tissues in internal compartments. Together, these results indicate that the diversity of fungal communities associated with camas is similar in below-ground tissues regardless of the habitat in which they are grown, whereas the diversity in soils or above-ground tissues varies significantly among habitats.

Disparate camas habitats and edaphic characteristics. The PCA of the leaf, tunic, and root fungal communities indicated that the mitigation, swale, and savanna habitats clustered closely, and

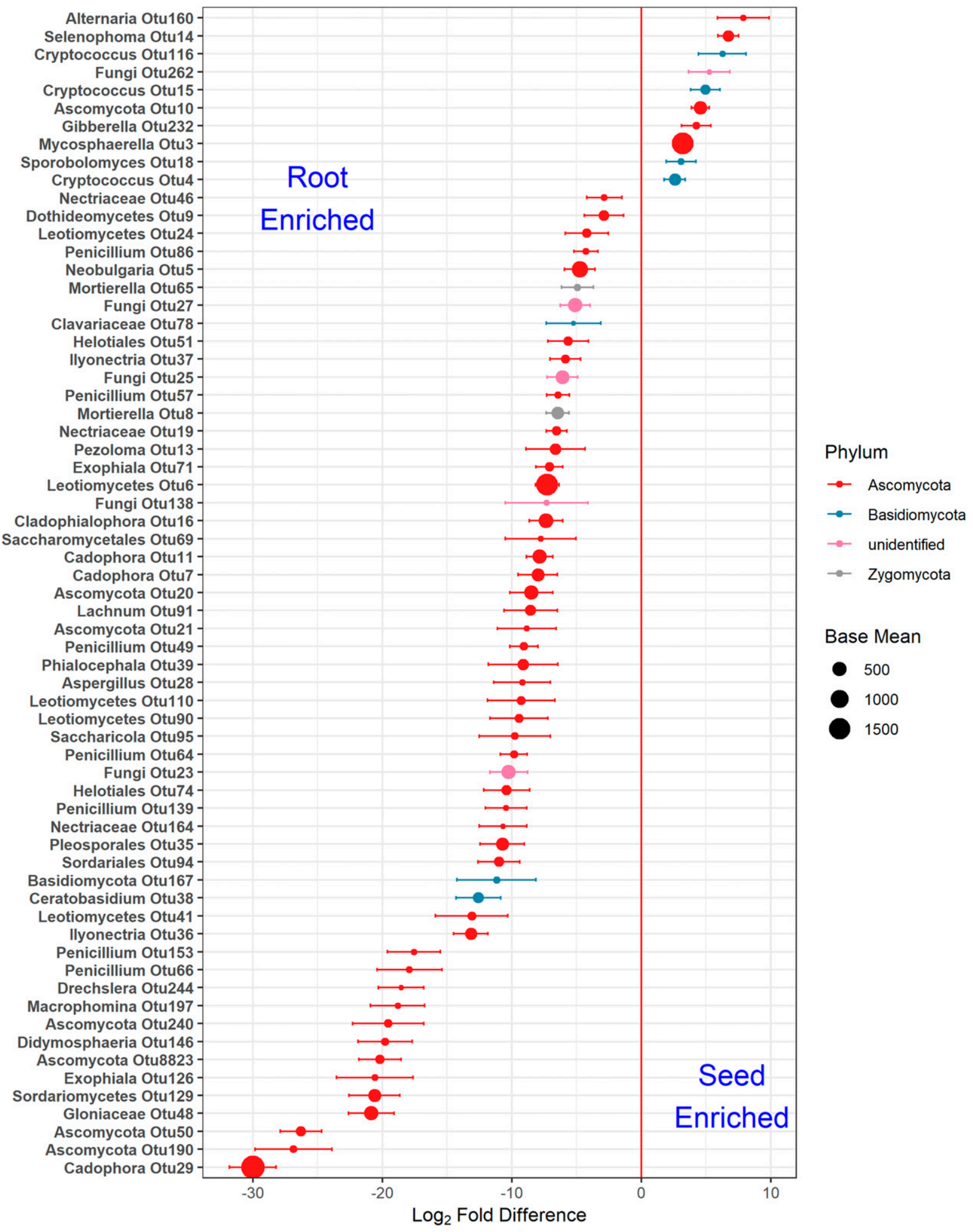

Fig. 8. Distribution of $\log _{2}$ fold changes indicate fungal operational taxonomic units (OTUs) differentially detected in camas roots compared with camas seeds across six camas habitats across the Pacific Northwest U.S.A. Base means show the normalized sequence counts in each OTU. Only OTUs with base means $>30$ and Wald test adjusted $P<0.1$ are reported. Standard error bars display variance within each sample type with five replicate samples/habitat. 
the serpentine, meadow, and garden fungal communities were each distinct (Figs. 3B, 4B, and 5C). The PCA of the rhizosphere fungal communities showed that taxa affiliated with the garden, savanna, and serpentine clustered closely, while the meadow, mitigation, and swale rhizosphere fungal communities were more distinct (Fig. 5D).

The garden habitat was unique among the six habitats because this site did not experience seasonal saturated soils of flooded soil

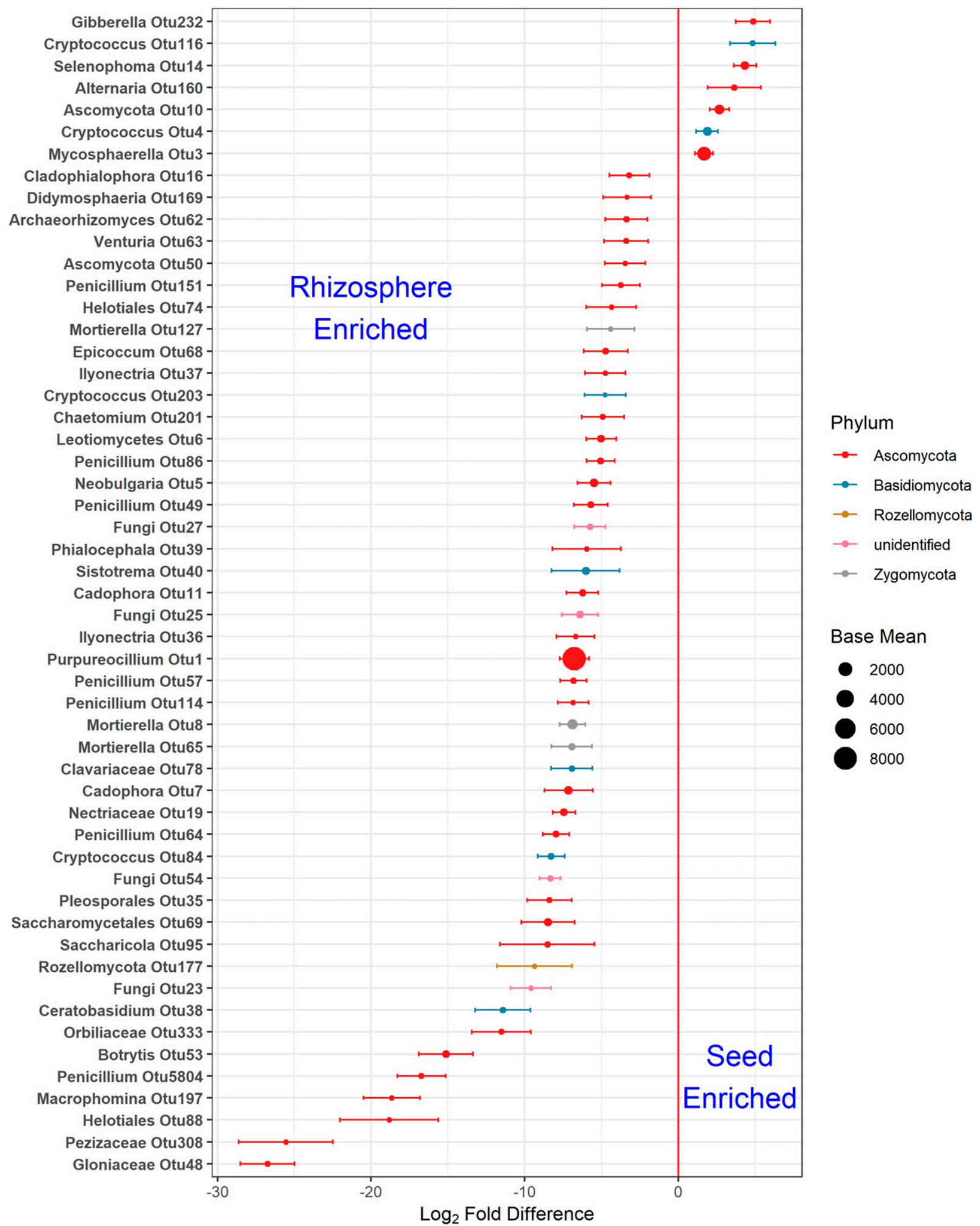

Fig. 9. Distribution of $\log _{2}$ fold changes indicate fungal operational taxonomic units (OTUs) differentially detected in camas rhizospheres compared with camas seeds across six camas habitats across the Pacific Northwest U.S.A. Base means show the normalized sequence counts in each OTU. Only OTUs with base means $>30$ and Wald test adjusted $P<0.1$ are reported. Standard error bars display variance within each sample type with five replicate samples/habitat. 
conditions in winter and early spring. The soil of the garden habitat was also composed of greater percentage silt than clay in the soil profile (Supplementary Table S10). The serpentine habitat was the only habitat in which the soil had a greater percentage sand compared with percent silt and clay. Soils from the mitigation and swale had the lowest organic matter (less than 5\% compared with 6 to $17 \%$ for the other four sites). The $\mathrm{pH}$ for the meadow, swale and mitigation soil samples was more acidic (5.3 to 6.5) compared with the samples collected from the other habitats ( $\mathrm{pH} 6.4$ to 7.7), with only soil from the serpentine being alkaline ( $\mathrm{pH} 7.5$ to 7.7).

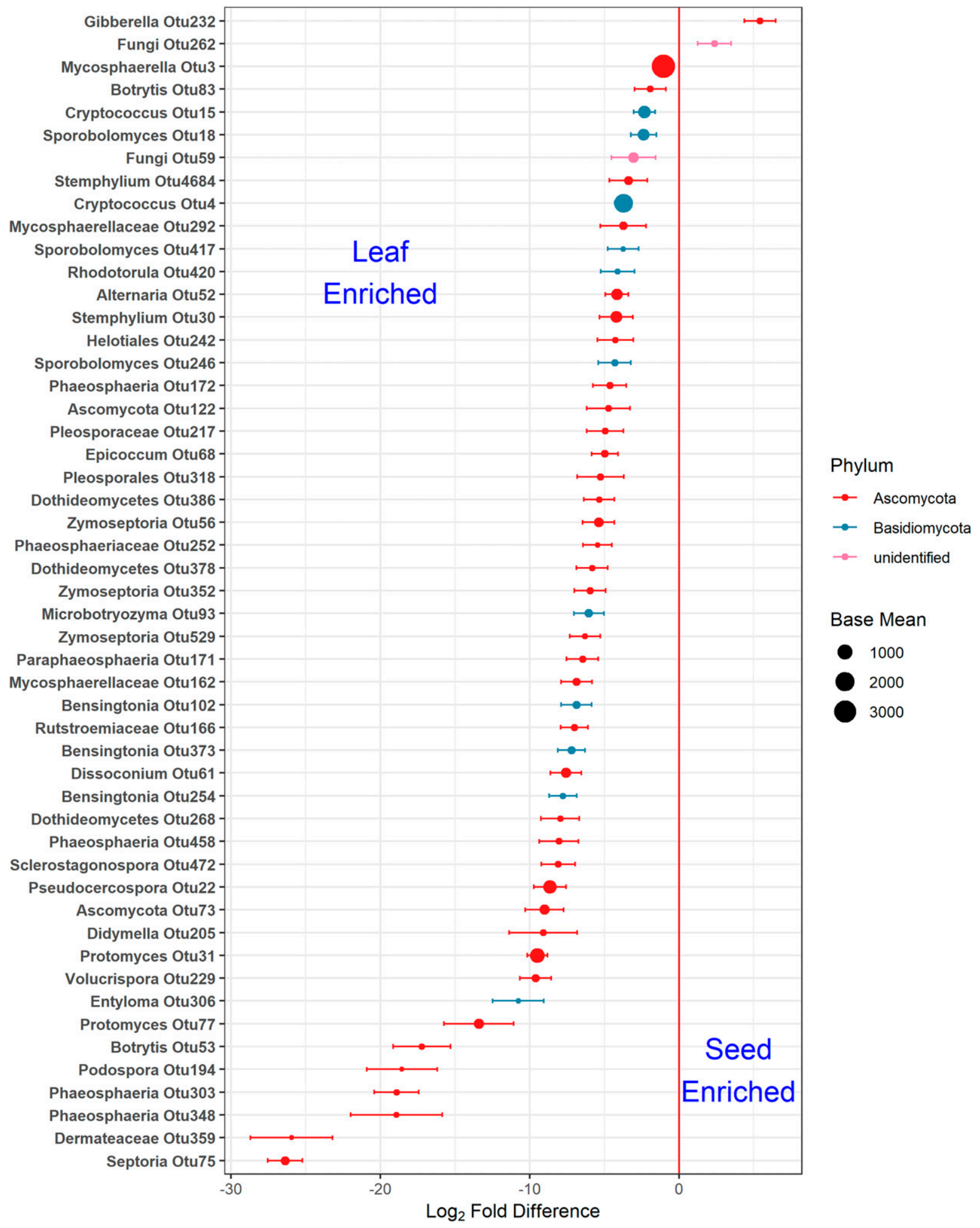

Fig. 10. Distribution of $\log _{2}$ fold changes indicate fungal operational taxonomic units (OTUs) differentially detected in camas leaves compared with camas seeds across six camas habitats across the Pacific Northwest U.S.A. Base means show the normalized sequence counts in each OTU. Only OTUs with base means $>30$ and Wald test adjusted $P<0.1$ are reported. Standard error bars display variance within each sample type with five replicate samples/habitat. 
There was a C:N ratio of $<17: 1$ for the soil samples taken from each habitat. The Kendall rank correlation analyses of the bivariate relationships between the edaphic variables revealed significant covariance between the following variables based on the linear relationships revealed in the correlation analysis and the Kendall tau coefficient $\mid z>0.16$, i.e., silt and sand (-0.70), clay and sand $(-0.40)$, clay and $\mathrm{pH}(-0.59), \mathrm{C}: \mathrm{N}$ ratio and $\mathrm{pH}(0.48)$, sand and $\mathrm{pH}(0.36), \mathrm{C}: \mathrm{N}$ ratio and sand (0.32), $\mathrm{C}: \mathrm{N}$ ratio and clay $(-0.34)$, and C:N ratio and organic matter (0.52) (Supplementary Fig. S3).

\section{DISCUSSION}

This study explored camas-associated fungal communities obtained from diverse camas tissues and associated soils sampled from biogeographically distinct wetland populations. Different wetland habitat sites were a strong driver of fungal community composition within the sample types. Taxa that preferred camas leaves were distinct from those inhabiting root, tunic, rhizosphere, and soil communities. Tunic tissue harbored known mycorrhizal taxa not found in the roots. There were notably fewer taxa found in the seed communities compared with other plant tissues or soil communities. Fungi found in common among the seeds, leaves, roots, and rhizospheres included endophytes, saprophytes, and yeasts although relatively few taxa were shared across all habitats. Characterizing fungal taxa in the seed, leaf, root, and rhizosphere samples gives new insight into the fungal communities that support camas populations in the ephemeral soil moisture conditions of wetland habitats in the PNW. Although this technology can identify OTUs to the family and sometimes identify to the genus level, there is often a large amount of functional diversity in these groups and the expression of such functions can often be environment specific. Nevertheless, some inferences can be made in terms of the life strategy of these fungi.

Only a small number of fungal taxa were found associated with camas populations growing in every habitat. But there was a strong effect of location on communities, with a common pattern of clustering for the tunic, leaf, and root communities. The swale, mitigation, and savanna sites tended to cluster together on the PCA biplots (Figs. 3, 4, and 5A). Camas was moved from the swale to the mitigation site, which are adjacent geographically, and all three locations have had agriculture disturbance and are seasonally flooded. However, for the rhizosphere, the mitigation and swale communities separated. This could be due to the fact that when transplanted, the camas bulbs carried a common root and tunic community to the new location, but the rhizosphere may have recruited a different community from the surrounding soil. The serpentine, garden, and meadow had distinct clustering for all the tissue types. The serpentine site had a distinct soil type, the garden site was cultivated but never flooded, and the meadow site was probably the most natural and pristine of all the locations. Hence, fungal communities are driven by biogeographic patterns and are derived primarily from characteristics of the local environment (Klaedtke et al. 2016).

Fungi play a key role in the mineralization process that is intimately coupled to litter decomposition in wetland ecosystems (van der Valk 2012). Sloughed off camas tissue that remains in proximity to the perennial bulb in the soil is likely to support the activity of saprophytic fungal taxa (Lareen et al. 2006; Rees 1972). Camas

TABLE 1

Shannon diversity indices of sample types (plant parts) at different locations ${ }^{y}$

\begin{tabular}{|c|c|c|c|c|c|c|}
\hline Sample & $\begin{array}{c}\text { Albion } \\
\text { Garden }\end{array}$ & $\begin{array}{c}\text { CaveJ } \\
\text { Serpentine }\end{array}$ & $\begin{array}{l}\text { Dump } \\
\text { Swale }\end{array}$ & $\begin{array}{l}\text { Gbeach } \\
\text { Savanna }\end{array}$ & $\begin{array}{c}\text { Idaho } \\
\text { Meadow }\end{array}$ & $\begin{array}{l}\text { Mitigation } \\
\text { Mitigation }\end{array}$ \\
\hline Soil & $2.81 \pm 74 a b$ & $2.67 \pm 0.19 a b$ & $3.18 \pm 0.32 \mathrm{a}$ & $2.02 \pm 0.49 b$ & $2.65 \pm 0.52 a b$ & $3.27 \pm 0.61 \mathrm{a}$ \\
\hline Root & $2.46 \pm 0.85 a$ & $2.76 \pm 0.39 a$ & $2.63 \pm 0.33 a$ & $2.58 \pm 0.49 a$ & $2.48 \pm 0.16 a$ & $2.65 \pm 0.27 a$ \\
\hline Tunic & $2.21 \pm 0.25 a$ & $2.37 \pm 0.35 a$ & $2.24 \pm 0.29 a$ & $1.18 \pm 0.37 \mathrm{a}$ & $1.86 \pm 0.49 a$ & $2.01 \pm 0.72 \mathrm{a}$ \\
\hline Basal plate & $1.90 \pm 1.15 a$ & $2.04 \pm 0.79 a$ & $2.36 \pm 0.55 a$ & $1.49 \pm 0.84 \mathrm{a}$ & $2.16 \pm 0.69 a$ & $1.73 \pm 0.87 \mathrm{a}$ \\
\hline
\end{tabular}

y The diversity of root and basal plate communities did not vary significantly among locations.

z Diversity measures for seed and basal plate communities are based on $n=200$ sequences/sample, rather than $n=10,000$ for other tissue types.

TABLE 2

Richness of sample types (plant parts) at different locations

\begin{tabular}{|c|c|c|c|c|c|c|}
\hline Sample & $\begin{array}{l}\text { Albion } \\
\text { Garden }\end{array}$ & $\begin{array}{c}\text { CaveJ } \\
\text { Serpentine }\end{array}$ & $\begin{array}{l}\text { Dump } \\
\text { Swale }\end{array}$ & $\begin{array}{l}\text { Gbeach } \\
\text { Savanna }\end{array}$ & $\begin{array}{l}\text { Idaho } \\
\text { Meadow }\end{array}$ & $\begin{array}{l}\text { Mitigation } \\
\text { Mitigation }\end{array}$ \\
\hline Soil & $224 \pm 65 a b$ & $261 \pm 13 a$ & $150 \pm 59 b c$ & $113 \pm 47 c$ & $209 \pm 47 a b c$ & $155 \pm 58 b c$ \\
\hline Root & $114 \pm 32 a$ & $121 \pm 14 \mathrm{a}$ & $107 \pm 27 a$ & $88 \pm 33 a$ & $115 \pm 17 a$ & $102 \pm 30 a$ \\
\hline Tunic & $83 \pm 31 a$ & $70 \pm 31 a$ & $80 \pm 28 a$ & $56 \pm 22 a$ & $78 \pm 37 a$ & $65 \pm 25 a$ \\
\hline Basal plate ${ }^{z}$ & $21 \pm 18 a$ & $19 \pm 6 a$ & $23 \pm 8 a$ & $15 \pm 7 a$ & $22 \pm 10 a$ & $16 \pm 7 a$ \\
\hline
\end{tabular}

z Diversity measures for seed and basal plate communities are based on $n=200$ sequences/sample, rather than $n=10,000$ for other tissue types. 
litter decomposition likely begins with decaying plant tissues such as leaves, sloughed off tunic, and root tissues. Foliar endophytes, such as taxa within Dothideomycetes and Sordariomycetes (Arnold 2007), likely become important saprophytes involved in decomposition. The diversity of taxa found in camas roots commonly considered to be saprophytes included ascomycetous taxa of Cladosporium, Ilyonectria, Neobulgaria, Penicillium, Aspergillus, and Delicatula; basidiomycetous taxa comprised of Ceratobasidium, Coprinus, and zygomycetous taxa that consisted of Mortierella and Endogonales.

Since most fungal genera found in the study are obligate aerobes, the taxa that coexist with camas populations growing in these wetland soils have presumably adapted to fluctuating soil moisture levels. In periods of low oxygen soil conditions, fermentation of organic matter by yeast functioning as facultative anaerobes and bacteria play a role in the degradation of plant litter decomposition (Snoek and Steensma 2007; Verhoeven 2009). The fungal communities of camas leaves were rich in yeast taxa belonging to Cryptococcus, Sporobolomyces, and Microbotryozyma. Further, other yeasts were abundant components of camas root, tunic, and rhizosphere communities, such as Cryptococcus, Exophiala, Sporobolomyces, and Rhodotorula.

Plants may be preferentially colonized by certain beneficial fungi (Klaedtke et al. 2016; Leff et al. 2017). Rhizosphere and root communities shared many fungal families that varied in abundance among habitats. Interestingly, OTUs affiliated with Trichocomaceae (Penicillium and Aspergillus), Hypocreales (Ilyonectria and Trichoderma), Helotiales (Cadophora and Tetracladium), and Herpotrichiellaceae (Cladophialophora and Exophiala) were more abundant in the root than in the rhizosphere communities. These results suggested that camas selects for root endophytic taxa from nearby fungal communities in the soil and rhizosphere (Leff et al. 2017; Rodriguez et al. 2009). Dark septate endophytes have been associated with various reported impacts on plant health (Jumpponen and Trappe 1998) in wetland fen plant communities (Weishampel and Bedford 2006) and rainforest environments (Bonfim et al. 2016). The dark septate endophyte taxa found in camas roots, tunics, and rhizospheres included Cadophora, Exophiala, Phialocephala, and Cladophialophora (Grünig et al. 2011; Jumpponen 2001; Rodriguez et al. 2009).

Mycorrhizae have also been associated with the promotion of wetland plant productivity and are demonstrated to expand the capabilities of the host plant to take up nutrients from wetland soils (Bohrer et al. 2004; Pfeifer-Meister et al. 2012). Mycorrhizal taxa in the camas roots, tunics, and/or rhizospheres included Serendipita, Sistotrema, Coprinus, Corticiaceae, Clavaria, Neobulgaria, Herpotrichiellaceae, and Endogonales (Arnold 2007; Cannon and Kirk 2007; Higgins et al. 2011). Like other endophytes, ectomycorrhizae can become saprophytic during tissue senescence and significantly influence litter decomposition and nutrient cycling (Cannon and Kirk 2007; Siddique and Unterseher 2016; Sieber 2007).

Camas seeds produced in the perennial nursery plot likely harbor fungal communities that co-occur with camas plants and facilitate the annual growth cycle of plant tissues and the decomposition of camas litter. When nursery seeds are then planted into wetland restoration sites, the seed may serve as the starting point for the establishment of a camas-associated mycobiome (Nelson et al. 2018). Fungal communities associated with camas seeds harbored three taxa that were ubiquitous in every habitat, namely Cladosporium, Selenophoma, and Cryptococcus. Mycorrhizal taxa associated with camas seeds that were also detected in the camas leaves, roots, and rhizospheres were Neobulgaria, Coprinus, and Sistotrema. Some of the notable endophytic taxa in these four sample types include genera that may form saprophytic associations with senescing plant tissues were Cladosporium, Alternaria, Fusarium, Cladophialophora, Penicillium, and Botrytis. Other diverse taxa detected in association with these four camas sample types included Lachnum, Metacordyceps, Leptosphaeria, and Pseudocercospora. Further investigation is warranted to assess whether the 68 taxa shared by the camas leaf and root, rhizosphere, and seed communities influence the local adaptation of camas seedlings to new wetland environments (Barret et al. 2015; Links et al. 2014).

\section{ACKNOWLEDGMENTS}

We thank S. Lupien for technical help.

\section{LITERATURE CITED}

Abarenkov, K., Nilsson, R. H., Larsson, K.-H., Alexander, I. J., Eberhardt, U., Erland, S., et al. 2010. The UNITE database for molecular identification of fungi-recent updates and future perspectives. New Phytol. 186:281-285.

Altschul, S. F., Gish, W., Miller, W., Myers, E. W., and Lipman, D. J. 1990. Basic local alignment search tool. J. Mol. Biol. 215:403-410.

Angiosperm Phylogeny Group. 2009. An update of the Angiosperm Phylogeny Group classification for the orders and families of flowering plants: APG III. Bot. J. Linneaus Soc. 161:105-121.

Arnold, A. E. 2007. Understanding the diversity of foliar endophytic fungi: Progress, challenges, and frontiers. Fungal Biology Reviews 21:51-66.

Barret, M., Briand, M., Bonneau, S., Préveaux, A., Valière, S., Bouchez, O., Hunault, G., Simoneau, P., and Jacques, M. A. 2015. Emergence shapes the structure of the seed microbiota. Appl. Environ. Biol. 81:1257-1266.

Beckwith, B. R. 2004. The queen root of this clime: Ethnoecological investigations of blue camas (Camassia leichtlinii (Baker) Wats, C. quamash (Pursh) Greene; Liliaceae) and its landscapes on southern Vancouver Island, British Columbia. Dissertation. University of Victoria.

Bell, A., and Bryan, A. 2008. Plant Form: An Illustrated Guide to Flowering Plant Morphology. Timber Press, Inc., London.

Bohrer, K. E., Friese, C. F., and Amon, J. P. 2004. Seasonal dynamics of arbuscular mycorrhizal fungi in differing wetland habitats. Mycorrhiza 14:329-337.

Bonfim, J. A., Vasconcellos, R. L. F., Baldesin, L. F., Sieber, T. N., and Cardoso, E. J. B. N. 2016. Dark septate endophytic fungi of native plants along an altitudinal gradient in the Brazilian Atlantic forest. Fungal Ecol. 20:202-210.

Borcard, D., Gillet, F., and Legendre, P. 2011. Numerical Ecology with R. Springer, New York.

Boyer, L. 2008. Providing native plant diversity to the Willamette Valley ecoregion: No-tech, low-tech, and old-tech seed production methods. Native Plants J. 9:230-240.

Bridgham, S. D., and Lamberti, G. A. 2009. Ecological dynamics III: Decomposition in wetlands. Chapter 15 in: The Wetland Handbook. E. Maltby and T. Barker, eds. Wiley-Blackwell, West Sussex.

Cannon, P. F., and Kirk, P. M. 2007. Fungal Families of the World. CAB International, Singapore.

Cherry, J. A. 2011. Ecology of wetland ecosystems: Water, substrate, and life. Nat. Educ. Knowl. 3:16.

Crocker, E. V., Lanzafane, J. J., Karp, M. A., and Nelson, E. B. 2016. Overwintering seeds as reservoirs for seedling pathogens of wetland plant species. Ecosphere 7:e01281.

Dise, N. B. 2009. Biogeochemical dynamics III: The critical role of carbon in wetlands. Chapter 11 in: The Wetland Handbook. E. Maltby and T. Barker, eds. Wiley-Blackwell, West Sussex.

Edgar, R. C. 2010. Search and clustering orders of magnitude faster than BLAST. Bioinformatics 26:2460-2461.

Edgar, R. C. 2013. UPARSE: Highly accurate OTU sequences from microbial amplicon reads. Nat. Methods 10:996-998.

Gardes, M., and Bruns, T. D. 1993. ITS primers with enhanced specificity for basidiomycetes-Application to the identification of mycorrhizae and rusts. Mol. Ecol. 2:113-118.

Grünig, C. R., Queloz, V., and Sieber, T. N. 2011. Structure of diversity in dark septate endophytes: From species to genes. Pages 3-30 in: Endophytes of Forest Trees. A. M. A. M. Pirttilä and A. C. Frank, eds. Springer, Dordrecht. Hebda, R. 1992. Camassias of Vancouver Island, Canada, and their cultivation. Pages 55-65 in: Lilies and Related Plants Anniversary Issue. A. F. Hayward, ed. The Royal Horticultural Society, Victoria. 
Higgins, K. L., Coley, P. D., Kursar, T. A., and Arnold, A. E. 2011. Culturing and direct PCR suggest prevalent host generalism among diverse fungal endophytes of tropical forest grasses. Mycologia 103:247-260.

Hurley, C. 2012. gclus: Clustering Graphics. R package version 1.3.1.

Jumpponen, A., 2001. Dark septate endophytes-Are they mycorrhizal? Mycorrhiza 11:207-211.

Jumpponen, A., and Trappe, J. M. 1998. Dark septate endophytes: A review of facultative biotrophic root-colonizing fungi. New Phytol. 140:295-310.

Klaedtke, S., Jacques, M. A., Raggi, L., Préveaux, A., Bonneau, S., Negri, V., et al. 2016. Terroir is a key driver of seed-associated microbial assemblages. Environ. Microbiol. 18:1792-1804.

Klinkenberg, B. 2017. E-Flora BC: Electronic Atlas of the Flora of British Columbia. Lab for Advanced Spatial Analysis. Department of Geography, University of British Columbia, Vancouver.

Kolde, R. 2011. Package 'pheatmap'. http://cran.r-project.org/web/packages/ pheatmap/pheatmap.pdf

Krueger, J. J., Bois, S. T., Kaye, T. N., Steeck, D. M., and Taylor, T. H. 2014. Practical guidelines for wetland prairie restoration in Willamette Valley, Oregon: Field-tested methods and techniques. Cascadia Prairie-Oak Partnership. https://cascadiaprairieoak.org/documents/wetland-prairie-guide

Lareen, A., Burton, F., and Schäfer, P. 2006. Plant root-microbe communication in shaping root microbiomes. Plant Mol. Biol. 90:575-587.

Leff, J. W., Lynch, R. C., Kane, N. C., and Fierer, N. 2017. Plant domestication and the assembly of bacterial and fungal communities associated with strains of the common sunflower, Helianthus annus. New Phytol. 214:412-423.

Links, M. G., Demeke, T., Grafenhan, T., Hill, J. E., Hemmingsen, S. M., and Dumonceaux, T. J. 2014. Simultaneous profiling of seed-associated bacteria and fungi reveals antagonistic interactions between microorganisms within a shared epiphytic microbiome on Triticum and Brassica seeds. New Phytol. 202:542-553.

Lyons, N., and Ritchie, M. 2017. The archaeology of camas production and exchange on the northwest coast: With evidence from a Sts'ailes (Chehalis) Village on the Harrison River, British Columbia. J. Ethnobiol. 37:346-367.

MacLay, A. M. 1928. Studies of the life history of Camassia quamash (Pursh) Greene. Master thesis. State College of Washington, Pullman.

Martin, M. 2011. Cutadapt removes adapter sequences from high-throughput sequencing reads.EMBnet. J. 17:10-12.

Nelson, E. B. 2018. The seed microbiome: Origins, interactions, and impacts. Plant Soil 422:7-34.

Nelson, E. B., Simoneau, P., Barret, M., Mitter, B., and Compant, S. 2018. Editorial special issue: The soil, the seed, the microbes and the plant. Plant Soil 422:1-5.

Oksanen, J. 2011. Multivariate analysis of ecological communities in R: Vegan tutorial. R package version 1.17-7.

Pfeifer-Meister, L., Johnson, B. R., Roy, B. A., Carreno, S., Stewart, J. L., and Bridgham, S. D. 2012. Restoring wetland prairies: Tradeoffs among native plant cover, community composition, and ecosystem function. Ecosphere 3:121.

Pribyl, D. W. 2010. A critical review of the conventional SOC to SOM conversion factor. Geoderma 156:75-83.
Rees, A. R. 1972. The Growth of Bulbs: Applied Aspects of the Physiology of Ornamental Bulbous Crop Plants. Academic Press, London.

Rodriguez, R. J., White, J. F., Arnold, A. E., and Redman, R. S. 2009. Fungal endophytes: Diversity and functional role. New Phytol. 182:314-330.

Rognes, T., Flouri, T., Nichols, B., Quince, C., and Mahé, F. 2016. VSEARCH: A versatile open source tool for metagenomics. PeerJ 4:e2586.

Siddique, A. B., and Unterseher, M. 2016. A cost-effective and efficient strategy for Illumina sequencing of fungal communities: A case study of beech endophytes identified elevation as main explanatory factor for diversity and community composition. Fungal Ecol. 20:175-185.

Sieber, T. N. 2007. Endophyte fungi in forest trees: Are they mutualists? Fungal Biol. Rev. 21:75-89.

Snoek, I. S., and Steensma, H. Y. 2007. Factors involved in anaerobic growth of Saccharomyces cerevisiae. Yeast 24:1-10.

Steeck, D. 2014. Camassia quamash establishment at Coyote Prairie: LEAP project progress report. City of Eugene Parks \& Open Space, Eugene, OR.

Stevens, M., Darris, D. C., and Lambert, S. M. 2001. Ethnobotany, culture, management, and use of common camas. Native Plants J. 2:47-53.

Thoms, A. V. 1989. The northern roots of hunter-gatherer intensification: Camas and the Pacific Northwest. Dissertation. Washington State University, Pullman, WA.

Turner, N. J., and Peacock, S. 2005. Solving the perennial paradox: Ethnobotanical evidence for plant resource management on the northwest coast. Keeping it Living: Traditions of Plant Use and Cultivation on the Northwest Coast of North America.D. Deur and N. Turner, eds. University of Washington Press, Seattle, WA and UBC Press, Vancouver.

Turner, N. J., and Turner, K. L. 2008. "Where our women used to get the food": Cumulative effects and loss of ethnobotanical knowledge and practice; case study from coastal British Columbia. Botany 86:103-115.

van der Valk, A. G. 2012. The Biology of Freshwater Wetlands, 2nd Ed. Oxford Press, Oxford.

Verhoeven, J. T. A. 2009. Wetlands biogeochemical cycles and their interactions. Chapter 11 in: The Wetland Handbook. E. Maltby and T. Barker, eds. Wiley-Blackwell, West Sussex.

Weddell, B. J. 2002. The Causes and Consequences of Loss of a Culturally Significant Resource: Seasonally Moist Meadows in the Palouse Region. Appendix 4 in Wetlands of the Palouse Prairie: Historical Extent and Plant Composition. G. Servheen, P. Morgan, B. Weddell, P. Gessler, and P. McDaniel, eds. Report funded by the USDI Environmental Protection Agency.

Weishampel, P. A., and Bedford, B. L. 2006. Wetland dicots and monocots differ in colonization by arbuscular mycorrhizal fungi and dark septate endophytes. Mycorrhiza 16:495-502.

White, J. R., and Reddy, K. R. 2009. Biogeochemical dynamics I: Nitrogen cycling in wetlands. Chapter 9 in: The Wetland Handbook. E. Maltby and T. Barker, eds. Wiley-Blackwell, West Sussex.

Zhang, J., Kobert, K., Flouri, T., and Stamatakis, A. 2014. PEAR: A fast and accurate Illumina paired-end read merger. Bioinformatics 30:614-620. 